\title{
Sistema de Realidade Aumentada para o treinamento em montagem e manutenção de equipamentos
}

\author{
Tiago De Gaspari, Antonio Carlos Sementille, João Fernando Marar \\ Faculdade de Ciências - Universidade Estadual Paulista Júlio de Mesquita Filho \\ (UNESP) \\ Caixa Postal 473 - 17033-360 - Bauru - SP - Brasil \\ \{gaspari, semente, fermarar\}@fc.unesp.br
}

\begin{abstract}
This work presents the development of an environment of teaching and training for assembly and maintenance of equipment supported by Augmented Reality, directed to the handling of complex equipment, which have an assembly process that requires prior training.
\end{abstract}

Resumo. Este trabalho apresenta o desenvolvimento de um ambiente de ensino e treinamento de montagem e manutenção de equipamentos apoiada por Realidade Aumentada, direcionado para o manuseio de equipamentos complexos, os quais possuem um processo de montagem que necessita de um treinamento prévio.

\section{Introdução}

O treinamento prático em montagem e manutenção em equipamentos complexos, como motores, conjuntos de peças hidráulicas ou até mesmo equipamentos eletrônicos, é uma atividade que demanda profissionais qualificados, muito tempo e é provável que todo o conhecimento necessário para realizar a tarefa seja perdido com o passar do tempo. Isso acontece devido ao fato de que cada equipamento possui um padrão de montagem único e quem está realizando o processo de montagem e/ou manutenção pode esquecer uma etapa, principalmente por falta de experiência ou devido à alta complexidade desta atividade.

Atualmente, com o auxílio da Realidade Aumentada é possível que um profissional consiga realizar uma montagem e/ou manutenção em um equipamento complexo apenas seguindo as instruções apresentadas pelo ambiente aumentado.

Segundo Kirner e Siscoutto (2007), Realidade Virtual (RV) pode ser definida de uma maneira simplificada, como a forma mais avançada de interface do usuário de computador até agora disponível. Para Aukstakalnis et. al (1992) a RV é uma forma das pessoas visualizarem, manipularem e interagirem com computadores e dados extremamente complexos.

A tecnologia conhecida como Realidade Aumentada (RA), por sua vez, é definida por Azuma (1997) como um sistema que: combina elementos virtuais com o ambiente real, é interativa, tem processamento em tempo real e é concebida em três dimensões. 
A RA possui, como principal característica, a imersão e grande capacidade de interatividade com o usuário. Por meio da sobreposição de objetos virtuais com o ambiente físico, propicia interações mais fáceis e naturais. Isso permitiu que a RA fosse considerada uma possibilidade concreta para a próxima geração de interfaces intuitivas. Com ela torna-se possível a análise de teorias, desempenho e estratégias em tempo real.

Considerando este contexto, o sistema proposto utiliza a RA como alternativa na realização de treinamentos, em substituição da utilização de manuais de instruções, como são realizados atualmente.

A utilização de modelos tridimensionais, com dimensões idênticas e texturas fiéis aos objetos reais, faz com que o usuário se sinta confortável ao utilizar um sistema de RA, onde ele possa identificar tanto objetos que ele possui certa afinidade, assim como objetos que desconheça. Isso possibilita processos de montagem, uma vez que o usuário precisa identificar qual objeto real o objeto virtual está referenciando.

O desenvolvimento de um sistema que combina o ambiente real com modelos em três dimensões poderá ser usado em áreas como arquitetura, design, entretenimento, educação, entre outras.

\section{Trabalhos Correlatos}

A seguir são apresentados os principais trabalhos correlatos encontrados na literatura.

No trabalho apresentado por Tang et. al (2003) é descrito um teste realizado para verificar a eficácia da RA na montagem de um objeto. $\mathrm{O}$ experimento consistiu em mostrar ao usuário qual é a próxima etapa de montagem do objeto, exatamente como deve ser realizada. Para isso, foram utilizados objetos 3D combinados com o ambiente real em um sistema baseado em RA. Três meios instrucionais foram testados: manuais impressos, instrução assistida por computador utilizando um monitor e utilizando um par de óculos para RA. Os resultados indicaram que as instruções 3D em sobreposição as peças de trabalho reais reduziram a taxa de erro em $82 \%$ em relação aos manuais. Outro estudo realizado foi a medição do esforço mental do usuário. Este indicou que o esforço mental utilizando RA diminuiu significantemente. Os autores sugerem que isto ocorreu porque parte do esforço mental ficou a cargo do sistema.

Coelho e Bahr (2005) mostraram como modelos feitos em CAD e LIDAR podem ser usados em aplicações de RA. Utilizando esses tipos de modelos, a inclusão de um objeto virtual em uma cena real tem um impacto bem menor para o usuário. Isso é de extrema importância para que os objetos virtuais possam se fundir ao ambiente real e criar um ambiente só, misto. Os autores escolheram estes tipos de modelos, uma vez que os mesmos possuem características como cor, formato, textura e formas idênticas aos dos objetos reais.

Já em Sääski et. al (2008), os autores destacaram os principais problemas encontrados ao realizar um sistema de RA para montagem de equipamentos. Um dos maiores desafios para a utilização desta tecnologia neste tipo de sistema, é a reutilização de dados de produtos existentes. Dados dos produtos são armazenados em sistemas que incluem todas as informações relevantes do mesmo (geometria 3D, estrutura, a estrutura de fabricação, a estrutura de montagem, etc.). Os autores relatam que muitas vezes os dados dos produtos se encontram em sistemas obsoletos, dificultando a integração entre 
estes e o sistema de RA. Além de representações 3D dos produtos, o conjunto de informações relacionadas com as orientações para a montagem, tais como anotações e animações, também deve ser considerado. Os estudos tiveram resultados promissores com os dois testes que foram realizados. Em um deles foi utilizado um quebra-cabeça simples, o qual deveria ser montado seguindo-se uma determinada ordem de peças. Em outro teste, em parceria com a indústria Deltatron Ltda, o usuário deveria montar um produto proposto pela indústria: um bloco hidráulico de determinado equipamento. Seguindo a linha de pensamento dos autores, os produtos a serem montados serão cada vez menores e mais complexos, além de possuir mais funcionalidades. Por isso é importante que atualizações no sistema que gera o ambiente aumentado sejam realizadas periodicamente, fazendo com que todos os produtos de determinada indústria, por exemplo, possam ser montados utilizando o sistema.

\section{Metodologia}

O sistema proposto foi desenvolvido utilizando-se a linguagem de programação C++ e as bibliotecas ARToolkit, OpenSceneGraph e OSGART. Essas bibliotecas são gratuitas e multiplataformas, facilitando a portabilidade do sistema criado.

O sistema foi desenvolvido de forma incremental e modular. Os módulos projetados foram:

- Módulo de Captura e Detecção de Marcadores: realiza a captura da imagem, proveniente de uma câmera (webcam), detecta os marcadores presentes no ambiente real e calcula suas posições e orientações;

- Módulo de Carregamento de Modelos 3D: realiza o carregamento de modelos de objetos tridimensionais para a posterior inserção no ambiente aumentado;

- Módulo de Carregamento da estrutura de animação: responsável por carregar as informações da ordem de montagem do equipamento, assim como as transformações geométricas que serão aplicadas aos modelos tridimensionais;

- Módulo de Animação de Modelos 3D: responsável por identificar e executar a animação adequada para cada passo da montagem;

- Módulo de Geração do Ambiente Aumentado: realiza a geração da cena final aumentada. É responsável pela construção dos elementos virtuais, cujas geometrias são obtidas do módulo de carregamento de modelos 3D;

- Módulo de Visualização do Ambiente Aumentado: responsável por exibir a cena aumentada no dispositivo de saída apropriado (display, óculos de RA ou projetor);

A Figura 1 apresenta a estrutura geral do sistema. 


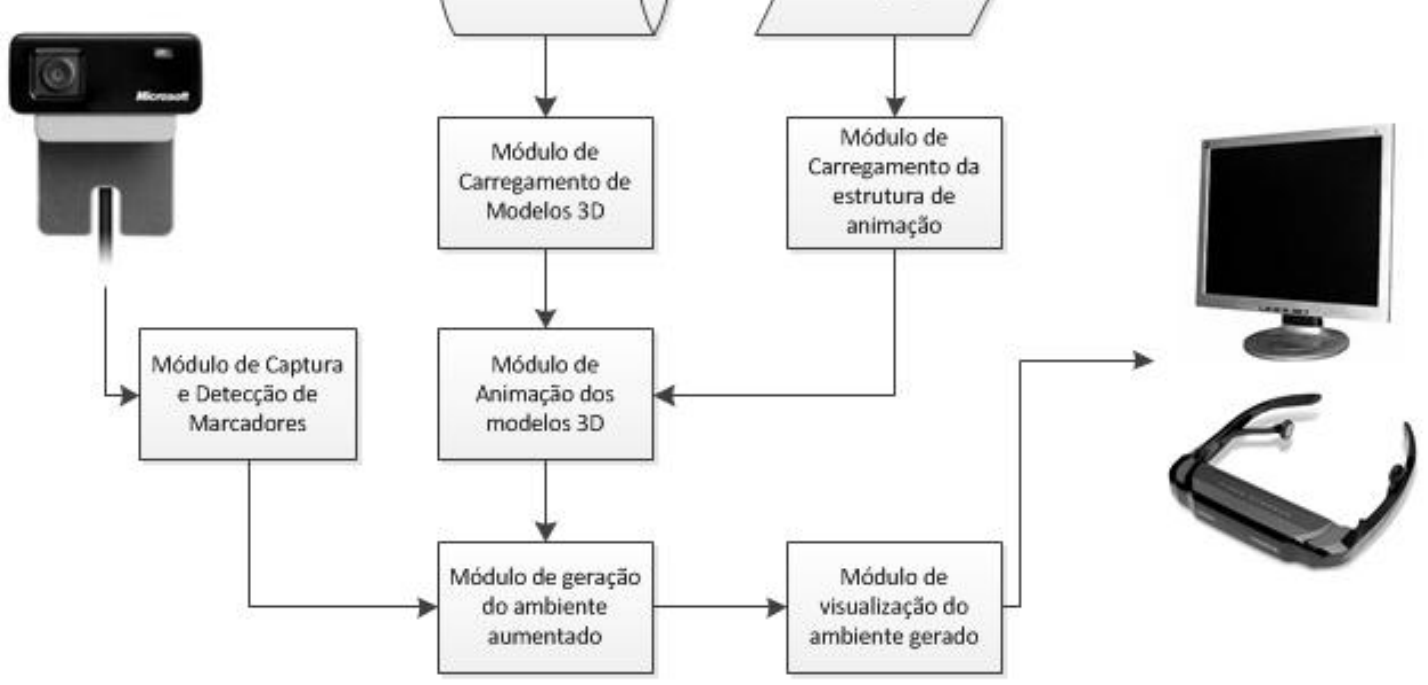

Figura 1. Estrutura geral do sistema

\section{Resultados}

O sistema desenvolvido permite o carregamento e visualização de modelos tridimensionais fiéis aos objetos reais e o posicionamento destes modelos em um ambiente aumentado em tempo real, assim como sua animação. Esta animação consiste na transformação de translação e rotação do objeto virtual que representa uma peça do processo de montagem ou desmontagem e simboliza o que deve ser feita com a peça real, ou em que posição a peça deve ser colocada.

O sistema permite a montagem de qualquer equipamento, no entanto, apenas como prova de conceito, optou-se pelo processo de montagem de microcomputadores.

A Figura 2 apresenta a cena aumentada gerada pelo sistema, em um dos passos da montagem do microcomputador. Destacam-se na figura, alguns quadros chaves da animação do movimento necessário para a instalação de um pente de memória. Além do posicionamento, as peças virtuais são animadas, mostrando com detalhes como elas devem ser encaixadas, ou giradas para a correta montagem do equipamento. 

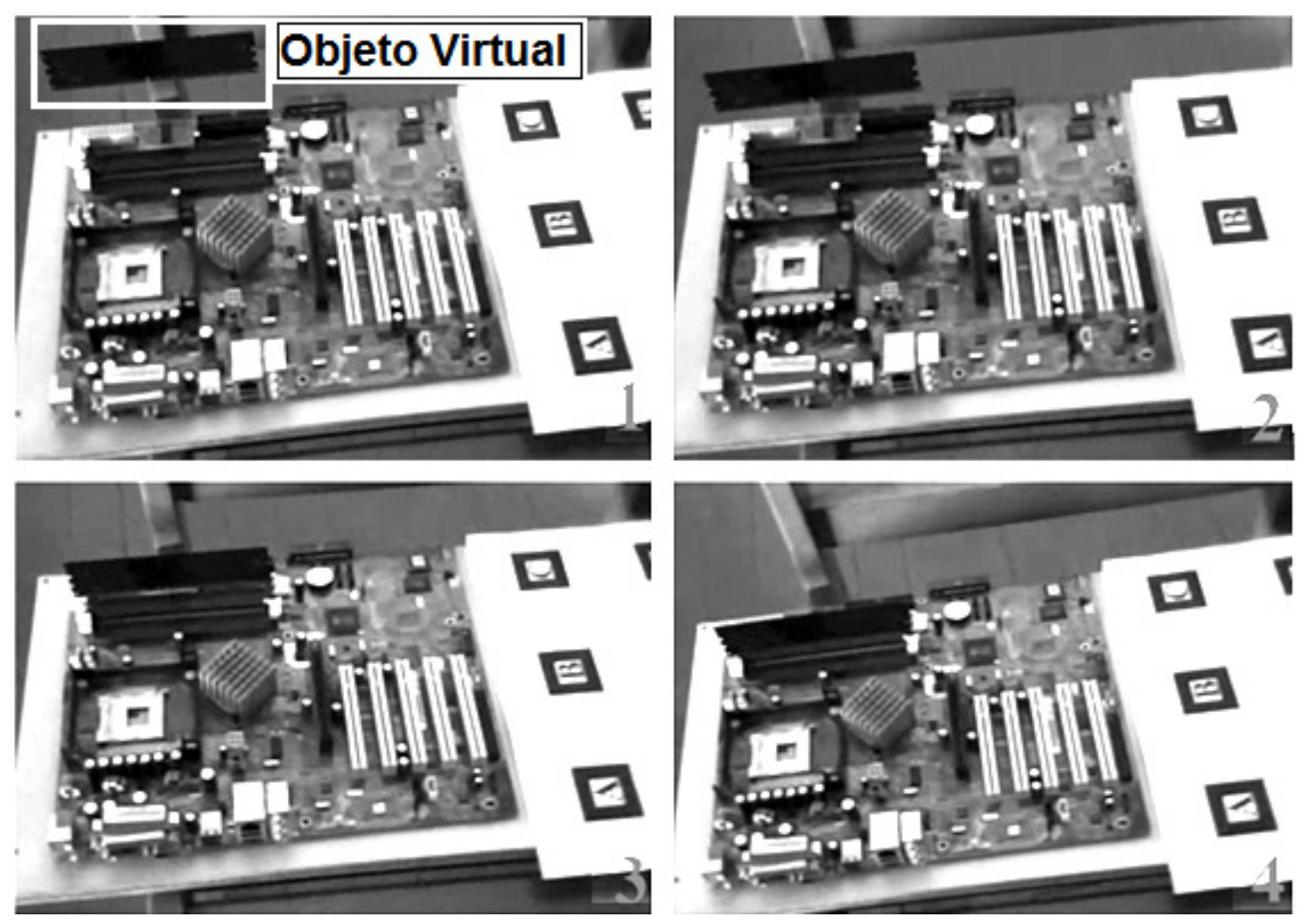

Figura 2. Um exemplo do funcionamento do sistema: quadros chaves da animação da instalação de um pente de memória

Os modelos tridimensionais que são inseridos na cena aumentada são configurados por meio de arquivos na linguagem XML (Extensible Markup Language). Nestes arquivos são armazenados dados como os nomes dos arquivos que representam os modelos tridimensionais previamente cadastrados, as transformações geométricas que constituem a animação destes modelos, a velocidade em que ocorre a animação e o correto posicionamento em relação aos marcadores reais.

Além da geração da imagem da cena aumentada com saída para um monitor convencional, foram realizados testes com um par de óculos de RV (Vuzix VR920) acoplado à uma webcam.

\section{Conclusões e Trabalhos Futuros}

Com o sistema desenvolvido é possível realizar-se a geração de objetos fiéis aos reais em um ambiente de RA, para o auxílio ao treinamento de processos de montagem e manutenção de equipamentos.

A utilização dos serviços das bibliotecas Artoolkit, OpenSceneGraph e OSGART, permitiu a criação de um sistema rico em detalhes, o qual aceita diversos modelos de objetos, e por utilizar o grafo de cena, oferece uma forma estruturada e otimizada de organização.

Como trabalhos futuros, está prevista a migração do sistema desenvolvido da plataforma atual para o uso em dispositivos móveis. Com a redução dos custos, o aumento do poder de processamento e o grande avanço na qualidade das câmeras 
presentes em smartphones e tablets, os dispositivos móveis vêm se tornando ótimas ferramentas para o uso de sistemas de RA. Além de possuírem uma mobilidade muito maior que os computadores desktops e notebooks, existem modelos de dispositivos móveis que possuem mais de uma câmera, além acelerômetros e giroscópios, viabilizando uma maior interação com o ambiente aumentado.

Outra funcionalidade do sistema que se deseja implementar é um módulo para o cadastro e configuração dos diversos passos para um processo de montagem. Neste módulo, o usuário poderá cadastrar manualmente os objetos tridimensionais, assim como as animações do mesmo e visualizar, previamente, como esses objetos serão apresentados no ambiente aumentado à outros usuários.

Por fim, é prevista a realização de testes do sistema com usuários voluntários que não possuam o conhecimento prévio do processo de montagem de determinados equipamentos, para que os mesmos realizem uma análise subjetiva da eficiência do sistema desenvolvido.

\section{Referências}

Aukstakalnis, S. e Blatner, D. (1992). Silicon Mirage; The Art and Science of Virtual Reality. Peachpit Press.

Azuma, R. (1997). "A Survey of Augmented Reality”. In Presence: Teleoperators \& Virtual Environments.

Coelho, A. H. and Bahr, H.-P. (2005). "Visualização de dados de CAD e LIDAR por meio de Realidade Aumentada". In Anais XII Simpósio de Sensoriamento Remoto. INPE.

Kirner, C. and Siscoutto, R. [Eds.] (2007). Realidade Virtual e Aumentada: Conceitos, Projeto e Aplicações. Petrópolis - RJ.

Saaski, J., Salonen, T., Hakkarainen, M., et al. (2008). Integration of Design and Assembly Using Augmented Reality. In: Ratchev, S.; Koelemeijer, S.[Eds.]. MicroAssembly Technologies and Applications SE. Springer US. p. 95-404.

Tang, A., Owen, C., Biocca, F. and Mou, W. (2003). "Comparative effectiveness of augmented reality in object assembly". In Proceedings of the conference on Human factors in computing systems - CHI '03. ACM Press. 